\title{
Designing their own Future: Teaching Students how to Design Aerospace Operations Research
}

\author{
Gillian N. Saunders-Smits ${ }^{1}$ and Ricky Curran ${ }^{2}$ \\ Faculty of Aerospace Engineering, Delft University of Technology, 2629 HS Delft, The Netherlands
}

This paper tells of the development of a course designed to help students set up their own operations research projects. The course was taught in a lecture format with much room for interaction and the students were required to make submit formal research plans for their operations research projects as well as literature review. The initial results from course evaluations show a significant improvement in student's self-perceived level of preparedness for their Master thesis as well as a high satisfaction with the course itself.

\section{Nomenclature}

$\begin{array}{ll}M d n & =\text { Median } \\ N & =\text { degrees of freedom } \\ n & =\text { number of respondents } \\ p & =\text { probability } \\ r & =\text { effect-size } \\ T & =\text { test statistic for Wilcoxon's matched pairs signed rank test } \\ t & =\text { test statistic for student's } t \text { - test } \\ z & =\text { z-score } \\ \sigma & =\text { standard deviation }\end{array}$

\section{Introduction}

E ngineering colleges world wide teach students the engineering basics such as Mechanics, Mathematics, and Chysics but also the true engineering skills of design and implementation of ideas into real products and services. In the process of their degree students are often taught to work in teams at the start but towards the end of their MSc degree they are also expected to work as independent individuals who can manage and carry out their own engineering research and design project. Many of these students go on to find careers in operations ${ }^{1}$.

In the Netherlands, often the approach by which students learn this important skill of independently running their own project is one of learning by doing. It is fair to say that this approach has both its advantages and disadvantages. Until recently the advantage of creating independent graduates ready for direct entry positions in the labor market outweighed the delay students often occurred in this process of learning to run independent projects. However, recent cuts in educational funding and announced penalty fees for students who take too long to complete their degrees have meant that a more pro-active approach needs to be taken by engineering universities in the Netherlands to shorten the time students take to complete their MSc thesis.

This paper will focus on the initiative started at the Faculty of Aerospace Engineering at Delft University of Technology (TUDelft) in which students are involved in a hands-on interactive course to help them design their own operations research projects. In the next section we will describe the details of the course design from learning objectives to assessment. In section III we will discuss the outcomes of the course evaluations as well as the

\footnotetext{
${ }^{1}$ Assistant Professor, Aerospace Structures, Faculty of Aerospace Engineering, Delft University of Technology, Kluyverweg1, 2629 HS Delft, The Netherlands, email: G.N.Saunders@tudelft.nl.

${ }^{2}$ Professor, Air Transport \& Operations, Faculty of Aerospace Engineering, Delft University of Technology, Kluyverweg 1, 2629 HS Delft, The Netherlands, email: R.curran@tudelft.nl, AIAA senior member.
}

American Institute of Aeronautics and Astronautics 
lecturers' experiences of the first year of running the course. The paper will conclude with some conclusions about the course's added value as well as recommendations for future implementation both at TUDelft and elsewhere.

\section{Course Design}

The master degree in Aerospace Engineering (www.lr.tudelft.nl) is a two year degree which can be split into two. The first year primarily consists of courses and exercises allowing the student to specialize on their chosen area of expertise. The second year has only two parts; a three months internship at a company or research institute and a seven month Master thesis in which the student has to prove their ability to independently carry out research. The course on designing operations research has therefore been scheduled to be taught in the last semester of the first year to provide students with an opportunity to make a successful start of their thesis.

The course was designed from the point-of-view that many students have indicated in the past that it takes them a long time to get organized in their thesis. At the same time many students who choose to do their MSc thesis on an aerospace operations related topic often choose to do so in industry in a set six or nine month period, making good planning essential as there is little time to waste. It is equally important that in that partnership between industry and academia that the needs of both partners are met in terms of deliverables. Industry should be provided with a useful contribution to their operations and the student must perform work that satisfies the academic criteria set for an MSc thesis. It is up to the student carrying out their thesis research to manage all these different facets. It is from this point-of-view that the course was created.

\section{A. Learning Objectives}

In close conjunction with fellow lecturers and industry partners a comprehensive set of learning objectives was formulated. At the end of the course each student will:

- be aware of the expectations of an MSc student

- be able to formulate a research question and a research aim

- be able to set up a research plan for their MSc thesis

- be able to write a literature review based on the research plan with a view to select appropriate methodologies for their MSc thesis

- based on initial problem, design, set up, run, analyze, manage and evaluate a research project

\section{B. Course Set up}

The course is a 2 EC (European Credits) course, with a whole academic year consisting of 60 EC. The workload of the course is 56 hours. As a teaching format interactive lectures were chosen, allowing for the effective mix of transferring knowledge and discussion. A total of seven lectures over a seven week period were designed, each dealing with their own topic as can be seen in Table 1. The course is accompanied with a text book on designing research projects from colleagues at the Radboud University of Nijmegen in the Netherlands, which outlines to students the need for structuring plans and formulating research questions ${ }^{2}$ based on their own considerable expertise in operations and research methods.

Table 1. Course Overview

\begin{tabular}{|c|c|c|}
\hline Lecture & Subject & Content \\
\hline 1 & Research Design in MSc & Stages of a project, research questions, strategy \\
\hline 2 & Research Methods & Quantitative \& qualitative methods, data collection etc. \\
\hline 3 & Data Analysis & $\begin{array}{l}\text { Quantitative \& qualitative methods using SPSS } \\
\text { example }\end{array}$ \\
\hline 4 & Validation \& Verification & How to validate \& verify your work? \\
\hline 5 & Project Management & $\begin{array}{l}\text { How to manage your project and your thesis progress. } \\
\text { Project plan peer review }\end{array}$ \\
\hline- & Library course & $\begin{array}{l}\text { How to carry out a scientific literature review? } \\
\text { Differences between review and research }\end{array}$ \\
\hline 6 & $\begin{array}{l}\text { Lit. Review, Scientific Reporting \& } \\
\text { Presenting }\end{array}$ & $\begin{array}{l}\text { Lit. Review assignment discussion, Academic standards, } \\
\text { Reproducibility, Reporting styles }\end{array}$ \\
\hline 7 & Feedback session & Closing the loop on course. Feedback and Way Forward \\
\hline
\end{tabular}


The course is set up from the point-of-view that doing operations research is not that different from any design process they are already familiar with. Active use is made from previous knowledge of systems engineering and design, as well as referring to the state-of-the-art in the operations field. The first lecture introduces the concept of the thesis as a proof-of-competence to highlight that the students need to independently operate as an engineer, and it explains to the students what a good operations thesis is relative to a bad one. Attention is paid to the roadmap of a good thesis: starting from a problem, to sample, measure, analyse and conclude. Also, significant time is spent explaining to the students the definition of the language and glossary of research as well as the balance between theory and practice.

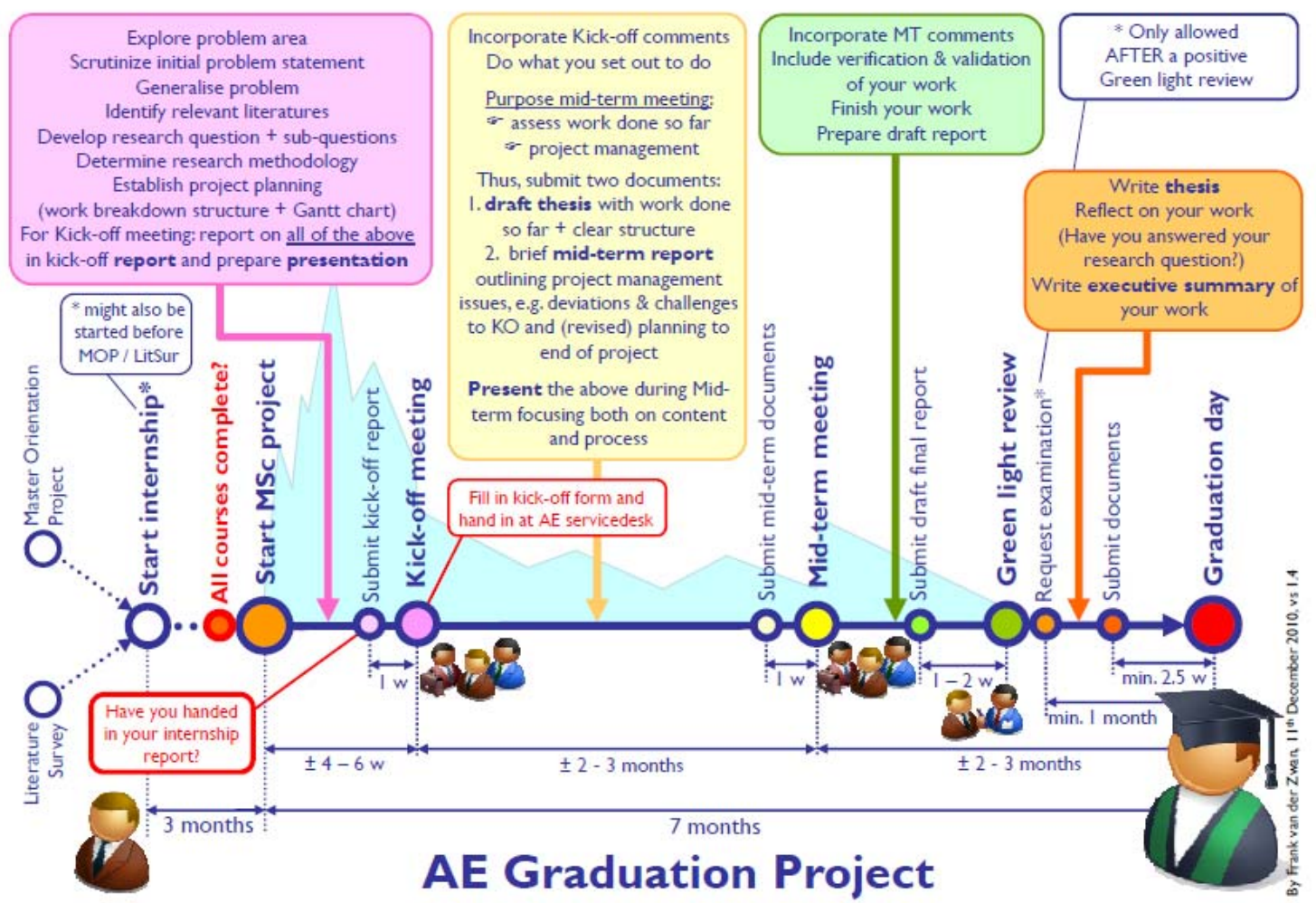

Figure 1. Overview of Master thesis project

In the second lecture the course then naturally flows towards research methods and data collection. Students are explained the importance of research aims and objectives, the framework in which the students will operate on in their research (students often graduate in companies), the pitfalls of formulating appropriate research questions, the different types of research they can choose from and also very importantly the operationalising of their research concepts and their research strategy.

During the third lecture the problem of data analysis is dealt with. Using a simple method of data gathering by means of an in-class questionnaire and making use of the SPSS ${ }^{\mathrm{TM}}$ software, students are informed of the pitfalls of data analysis and data interpretation. This is then naturally continued in the fourth lecture by addressing the concept of validation \& verification. In this lecture the aim is to make students more aware of the different levels of validity and how if they design their operations research appropriately they can not only solve the immediate problem at hand but also contribute to the larger body of science within their field and even outside of that.

The fifth lecture discussed the aspects of planning and project management. Although the students will have done project based assignments before, this is the first time where they are more or less in control of their own time and project management. A Master's thesis project typically lasts 7 months (see Figure 1) but many students experience delays often due to lack of structured planning or require extra time to ensure a better quality and end result. Students are provided with planning tools such as Gannt charts and Work Breakdown Structures as well as anecdotal evidence of how to avoid unnessary delays. They are also given the opportunity to peer review each other's draft project plans, which they are required to draw up, and learn from each other's feedback as this has been showed to be a proven way of increasing student's learning ${ }^{3}$. 
The Delft University of Technology library (www.library.tudelft.nl), one of the largest engineering libraries in Western Europe, is also involved in the course by providing an online information literacy course allowing students to fill the gaps on their knowledge and skills. This is then followed on by a lecture on the concept of a literature review and how it differs from a literature study and what its benefits are for students in their thesis when carried out properly. The lecture series is finished by a Question \& Answering session allowing students to interact further with staff on any remaining questions and issues they may have.

Next to the above, during the entire course, students are provided with information on academic standards, relevant structuring tools, anecdotes of past mishaps and general expectations of what an MSc thesis on Aerospace Operations should be. We also intend to newly include some testemonies from students currently performing their Masters thesis or already finished it.

\section{Course deliverables}

In order to complete the course students have to fulfill three assignments. The first is to follow the on-line Library course and pass the e-assessment associated with the course. The on-line library course has been developed by the TU Delft library for all MSc students.

Secondly, students are asked to write a research plan in which the set out the course of action they intend to follow in their thesis. The ten-page plan must contain a research background, a state-of-the-art literature review, research aim, research questions, a methodology section, a experimental set -up section and an outcome/relevance and results section.

Finally, students are asked to write a literature review in which they are asked to research an area of interest for their thesis research and set out the achievements already made in that area as well as challenges of interest by contrasting opposing views and linking the literature found to their own proposed research. Students are only allowed to use high quality, academic references.

The central idea behind these assignments is that students start preparing for their thesis and structure their thinking and ways of working accordingly. The assignments which differ greatly in topic are corrected using Rubrics developed for the course ${ }^{4}$.

\section{Results}

The course was run twice in the academic year 2010-2011 and some 70 students have completed the course. All students who attended the last lecture were asked to fill in a short course evaluation. All students who attended the class filled in the questionnaire. The response of these two evaluations was $n=33$, resulting in a response rate of $47 \%$. However, it should be noted that as the course was also made available through video streaming not all students attended the Monday morning 8.30 am class. This has affected the response rate.

Table 2. Course evaluation results (ranging from 1 = "very poor" to 5 = "excellent")

\begin{tabular}{lccc}
\hline & Mean & Mode & $\sigma$ \\
\hline Relevance of course & 4.5 & 5 & 0.568 \\
\hline Thoughts on course format & 3.74 & 4 & 0.729 \\
\hline Thoughts on level of interaction & 3.82 & 4 & 0.635 \\
\hline Thoughts on level of practical information & 4.03 & 4 & 0.951 \\
\hline Thoughts on level of theoretical research methodologies & 3.50 & 3 & 0.842 \\
\hline Thoughts on book & 3.34 & 3 & 0.814 \\
\hline Thoughts on project plan assignment & 4.21 & 4 & 0.696 \\
\hline Thoughts on literature review assignment & 3.73 & 4 & 0.868 \\
\hline
\end{tabular}

The students indicated that the relevance of the course to their MSc thesis was clear as can be seen from table 2 . Also students were generally positive about the format of the course, the book, the assignments, and the level of 
information (see table 2). The standard deviations for the level of practical information, theoretical research methods, the literature review assignment and the book are large indicating a large spread in answers.

Students were also asked to rate their perceived level of preparedness for their MSc thesis before and after the course. It can be seen from table 3 that an increase in level of preparedness of 2.7 was reported on a scale of 1 to 10 . In order to see if this increase was significant Wilcoxon's signed rank test ${ }^{5}$ was carried out. It was not possible to carry out the usual dependent t-test as the data was not normally distributed. The results show that the level of preparedness for the MSc thesis after the course $(M d n=7.591)$ had significantly increased compared to the level of preparedness for the MSc thesis prior to the course $(M d n=4.864), T=555, p<0.05, z=4.927$ and $r=0.86$. The effect size $r$ is much larger than Cohen's benchmark of 0.5 so the effect is large ${ }^{5}$.

\section{Conclusion}

From the results of the previous section it can be concluded that the course significantly adds to the level of preparedness of students for their thesis in operations. It also shows that the students are highly satisfied with the course set up overall. That does not mean however, that there are no improvements to be made. For next year the course will be amended to provide more structure on the literature review assignment, better tie ins of the classes with the book as well as more elaboration on the theoretical research methods. All in all though the authors believe the course can be considered a success!

\section{References}

${ }^{1}$ Saunders-Smits, G.N., "Study of Delft Aerospace Alumni," Ph.D. Dissertation, Faculty of Aerospace Engineering, Delft University of Technology, Delft, The Netherlands, 2008.

${ }^{2}$ Verschuren, P. and Doorewaard, H., "Designing a Research Project," $2^{\text {nd }}$ edition, Eleven international publishing, The Hague, 2010.

${ }^{3}$ Biggs, John, "Teaching for quality Learning at University," $2^{\text {nd }}$ edition, Open University Press, Mc Graw-Hill education, Maidenhead, United Kingdom, 2004.

${ }^{4}$ Stevens, Dannelle D. and Levi, Antonia J., "Introduction To Rubrics - An Assessment Tool to Save Grading Time, Convey Effective Feedback and Promote Student Learning," Stylus Publishing, Virginia,2005.

${ }^{5}$ Field, Andy, "Discovering Statistics using SPSS for Windows (and Sex, Drugs and Rock 'n Roll)," 2nd Edition, SAGE publications, London, 2005 